\title{
SKELETAL LESIONS PRODUCED BY SEMICARBAZIDE AND EXPERIMENTAL ANALYSIS OF THE ACTION OF LATHYROGENIC COMPOUNDS
}

\author{
P. Ramamurti and H. E. Taylor, Vancouver, Canada \\ From the Department of Pathology, Faculty of Medicine, University of British Columbia, Vancouver
}

Laboratory animals fed on a diet containing either beta aminopropionitrile (BAPN) $\left(\mathrm{NH}_{2}\right.$. $\mathrm{CH}_{2} \cdot \mathrm{CH}_{2} \cdot \mathrm{CN}$ ), the toxic factor in sweet peas (Lathyrus Odoratus), or amino acetonitrile $\left(\mathrm{NH}_{2} . \mathrm{CH}_{2} . \mathrm{CN}\right)$, develop various skeletal lesions such as scoliosis, displacement of epiphyses, osteochondritis and dislocation of joints. The term osteolathyrism has been applied to these lesions (Selye 1957). In a previous report on the skeletal lesions produced by BAPN, it was suggested that they might be due to an alteration in the ground substance of the epiphysial plate and interference with endochondral ossification (Ramamurti and Taylor 1958a). Similar lesions produced by mercaptoethylamine $\left(\mathrm{NH}_{2} . \mathrm{CH}_{2} \cdot \mathrm{CH}_{2} \mathrm{SH}\right)$ have also been the subject of a previous study (Ramamurti and Taylor 1958b). According to Dasler (1958), semicarbazide $\left(\mathrm{NH}_{2}\right.$. NH. CO. $\left.\mathrm{NH}_{2}\right)$ also had lathyrogenic properties, but he did not describe the pathology of the lesions.

This report is a histological study of some aspects of the lesions produced by semicarbazide. Repetition of findings already published in connection with other lathyrogenic compounds will be avoided. The description will be confined to the epiphysial plate and an attempt will be made to demonstrate the mechanism of the spinal deformity. The action of the lathyrogenic compounds will be analysed in the light of a number of experiments performed in this laboratory.

\section{MATERIALS AND METHODS}

Fifty Wistar rats, three weeks old, freshly weaned and weighing between thirty-five and forty grammes, were divided into two groups:

Group I-Twenty-five rats were fed on a standard diet (Ration No. 10 supplied by Buckerfield Feed Company).

Group II-Twenty-five rats were fed on a standard diet with which semicarbazide hydrochloride was mixed so that it made a concentration of 0.3 per cent. in the diet.

The animals in each group were killed at the end of six weeks and radiographs were taken. The knee joint, shoulder joint and thoraco-lumbar spine were selected for histological study. The tissues were fixed in 10 per cent formol alcohol and decalcified with normal hydrochloric acid. Paraffin blocks were prepared and serial sections from each block were stained with haematoxylin and eosin, $0 \cdot 1$ per cent aqueous toluidine blue and periodic acid Schiff (McManus method).

\section{RESULTS}

All the experimental animals (Group II) showed advanced skeletal lesions (Fig. 1). These consisted of severe kyphoscoliosis, bowing of the long bones, displacement of epiphyses, dislocations of joints and periosteal new bone formation at the attachment of tendons and ligaments. The lesions were identical with those produced by BAPN, with the exception of the spinal deformity. The severe kyphoscoliosis was peculiar to the animals in the present experiment and consisted of a sharp curve involving a short segment of the spine, with the summit of the curve at the twelfth thoracic or first lumbar vertebra (Fig. 2). About two 
vertebrae above and below were included in the arc of the curve. This pattern was constant in all the animals of Group II. The angulation of the spine was so sharp that in some of the animals there was compression of the spinal cord and paraplegia. On the other hand animals on BAPN had a diffuse scoliosis without such a marked degree of kyphosis.

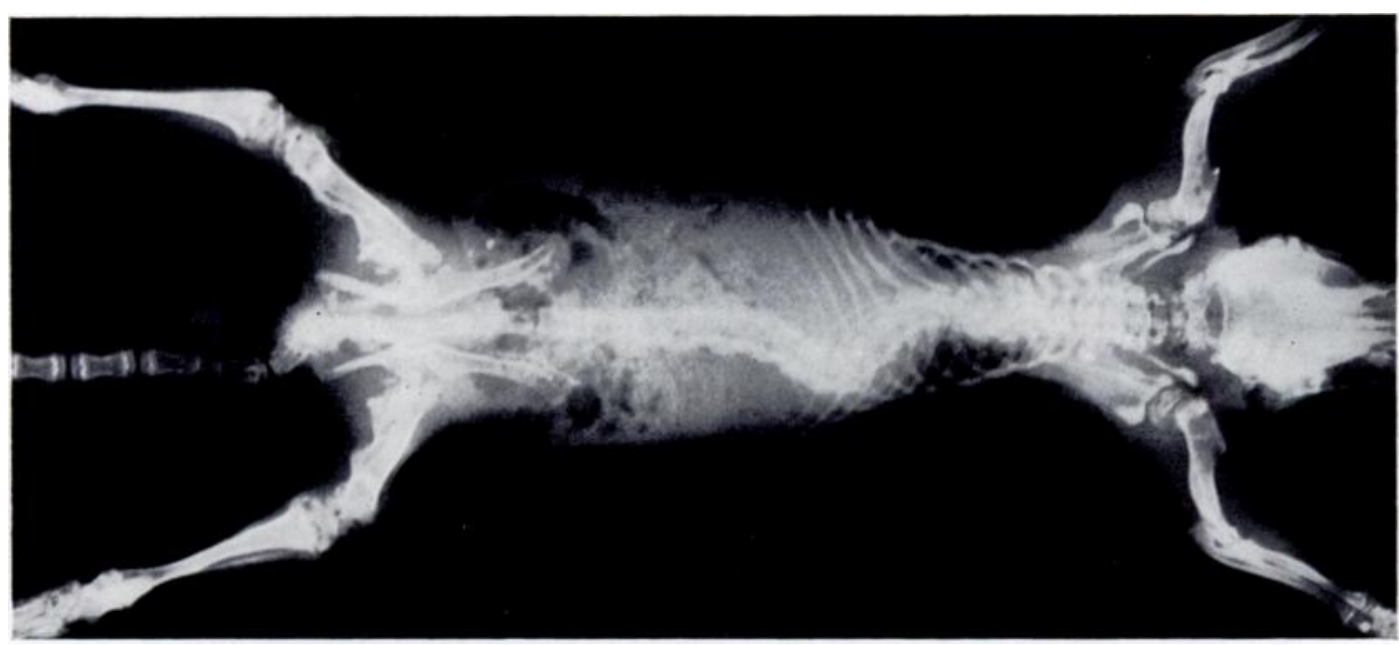

Fig. 1

Radiograph of a rat fed on semicarbazide for six weeks. The points to be observed are the severe scoliosis, the irregularity and displacement of both upper tibial and upper humeral epiphyses, and the periosteal new bone along the shaft of the femur, the infraglenoid part of the scapula and at the insertion of the deltoid on the shaft of the humerus.

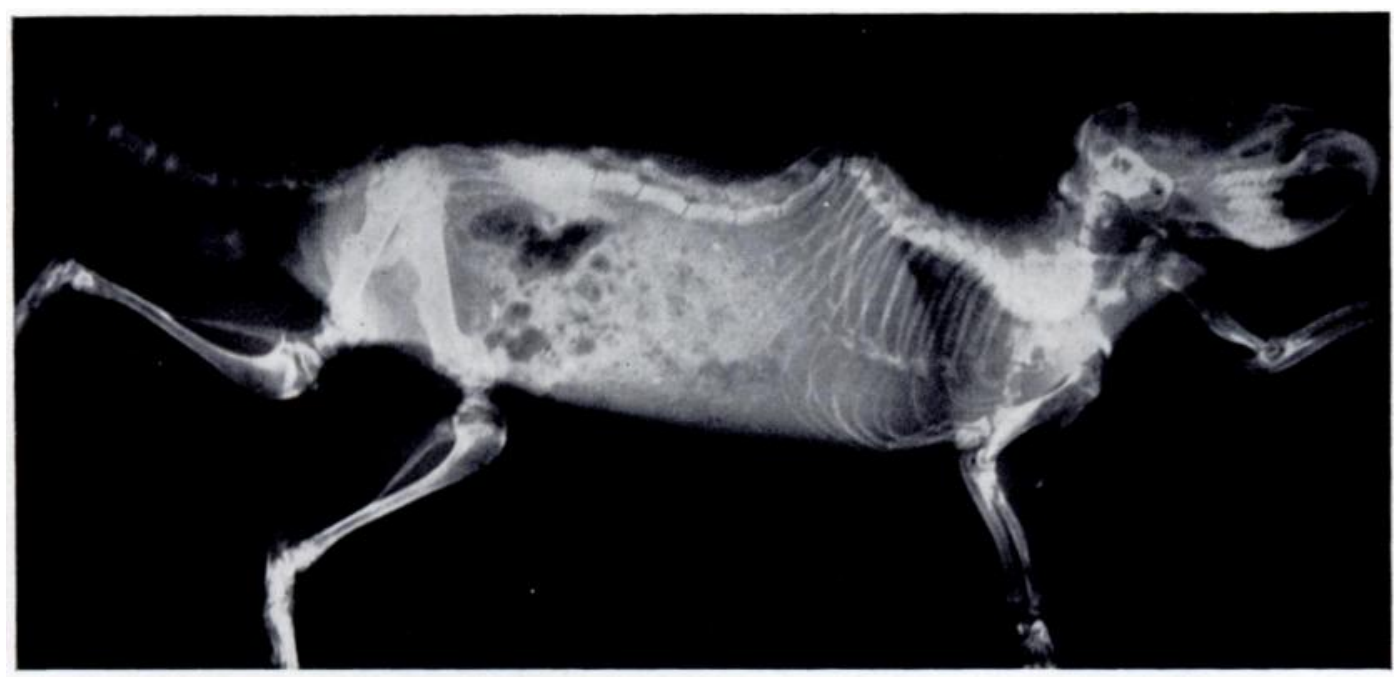

FiG. 2

Lateral radiograph of the same rat as in Figure 1. The sharp kyphosis involving a short segment of the thoraco-lumbar spine with the apex at the twelfth thoracic vertebra is shown very clearly.

Microscopically, the most advanced changes were noted in the lower end of the femur and the upper ends of the tibia and humerus. These were characterised by a marked widening and disorganisation of the epiphysial cartilage with a disruption of the various zones (Figs. 3 and 4 ). The zone of maturing cartilage was abnormally wide and accounted for the general enlargement of the plate (Fig. 5). There were tears in the matrix of the epiphysial cartilage, which permitted a shearing of the epiphysis through the cartilaginous plate, resulting in

Vol. $41 \mathrm{~B}$, NO. 3, AUGUST 1959 
displacement and angulation. There were linear areas of periodic acid Schiff positive staining material in the ground substance (Figs. 4 and 5). Various areas of decreased metachromasia were also seen but these were not constant.

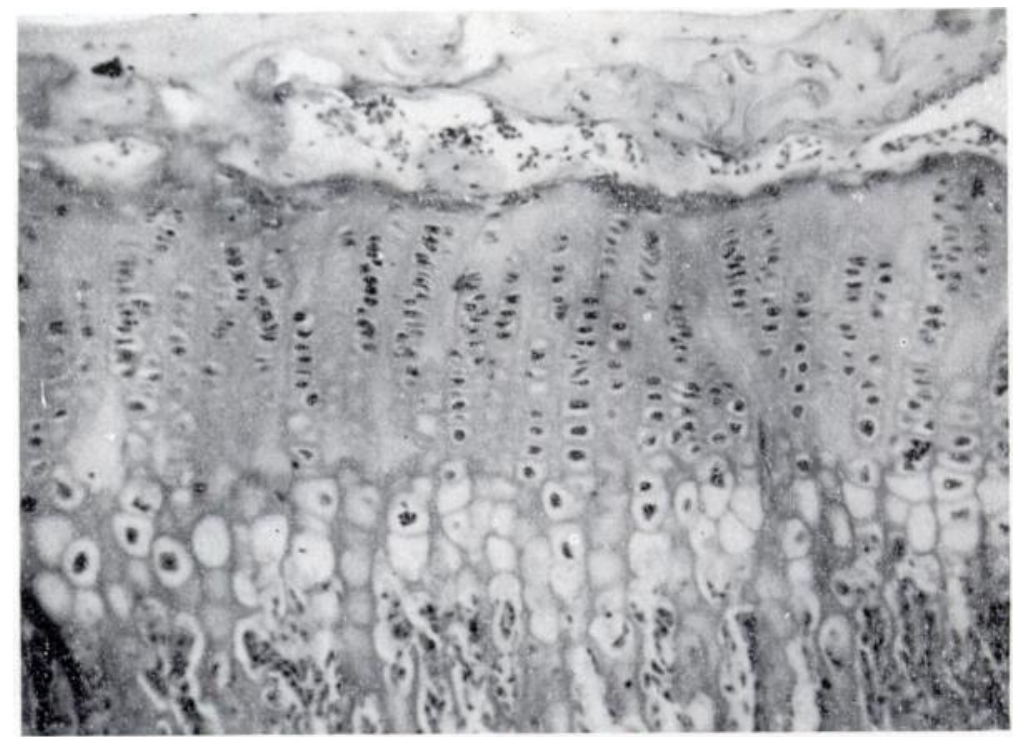

FIG. 3

The upper tibial epiphysis of a normal rat shows that the epiphysial plate is narrow and there is a regular and orderly arrangement of the various zones.

The matrix is periodic acid Schiff negative. (Periodic acid Schiff, $\times 150$.)

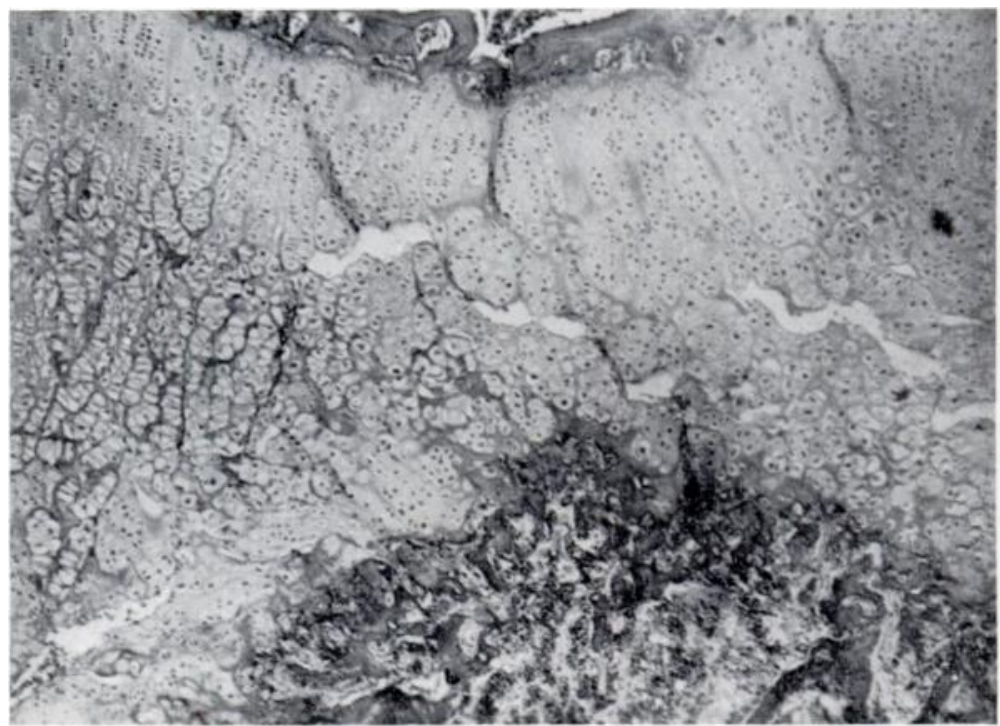

Fig. 4

The upper tibial epiphysial plate of a rat fed on semicarbazide for six weeks. There is a widening of the epiphysial cartilage with disorganisation of the various zones and tears in the matrix. Observe the linear areas of positive periodic acid Schiff material in the ground substance and compare with normal epiphysial plate shown in Figure 3. (Periodic acid Schiff, $\times 45$.)

The epiphysial changes described above were most severe in the long bones of the extremities. Though not so dramatic, they were also present in the epiphysial plates of the twelfth thoracic or first lumbar vertebra (Fig. 6). The enlargement of the plate and the 
disorganisation were not so marked, but there were tears, severe angulation and displacement at and through the epiphysial plate resulting in a well marked kyphosis. These changes were found only in the twelfth thoracic or first lumbar vertebra or occasionally in both. Perhaps,

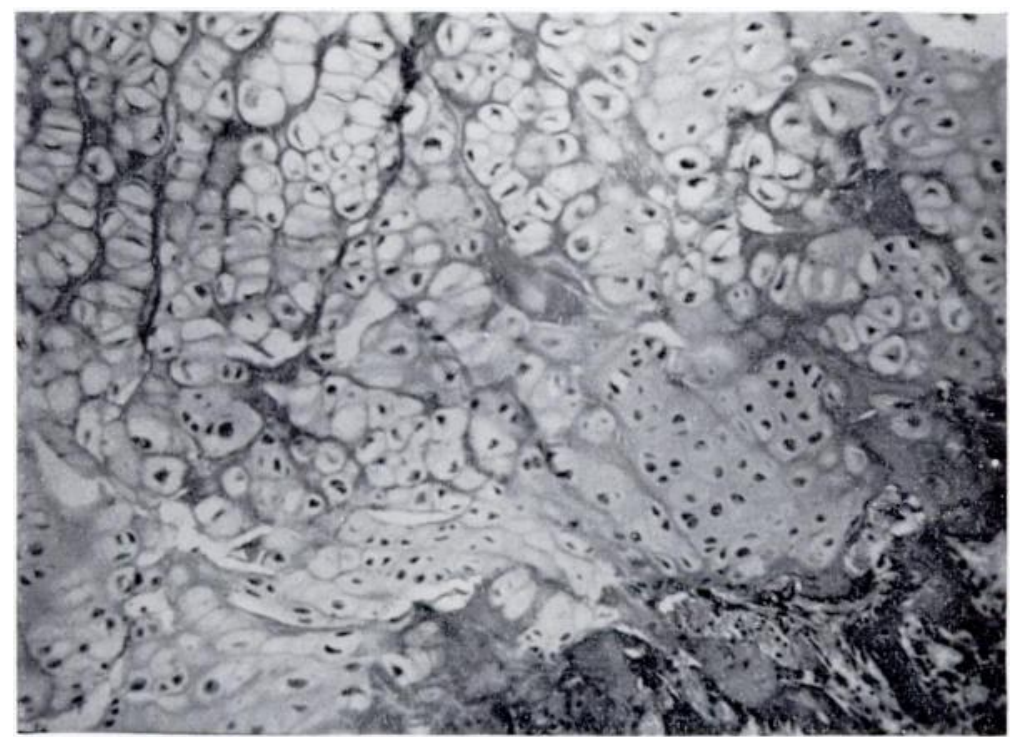

FIG. 5

High power of the same section as in Figure 4. The major portion of the widened epiphysial plate consists of the zone of maturing cartilage cells. Again observe the periodic acid Schiff positive material in the ground substance. (Periodic acid Schiff, $\times 110$.)

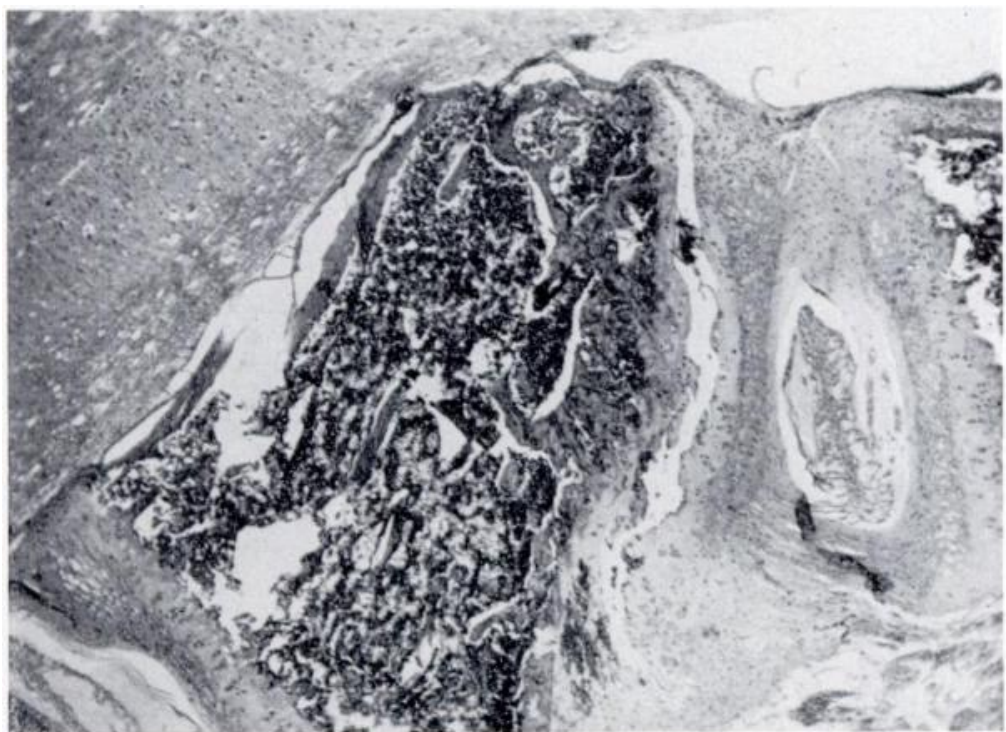

Fig. 6

A sagittal section through the spine at the level of the twelfth thoracic vertebra of a rat on semicarbazide for six weeks. There is disorganisation and a tear in the epiphysial plate through which the angulation occurs. The spinal cord at the top left of the picture is compressed. (Haematoxylin and eosin, $\times 30$.)

because of increased metabolic or mechanical stress, these particular vertebrae are more vulnerable. The epiphysial plates of the other vertebrae showed insignificant changes, but frequently degeneration of the annulus fibrosus of the intervertebral discs was noted in various segments of the spine.

VOL. 41 B, NO. 3, AUGUST 1959 


\section{DISCUSSION}

There has been some uncertainty about the mechanism of the spinal deformity in osteolathyrism. On the basis of a study of the spine in the animals on semicarbazide, it is clear that the kyphoscoliosis was due to a derangement and displacement at and through the epiphysial plate of the vertebra (Fig. 7). This clearly demonstrates that experimental changes in the epiphysial plates of vertebrae can be a cause for abnormal curvatures of the spine.

The mode of action of the lathyrogenic compounds is not known. In the light of a considerable number of experiments done in this laboratory and the great strides that have been made by other workers (Zambotti 1957) in the study of the biochemistry of the epiphysial plate, an attempt will be made to correlate the possible mode of action of these compounds with the metabolism of the epiphysial plate.

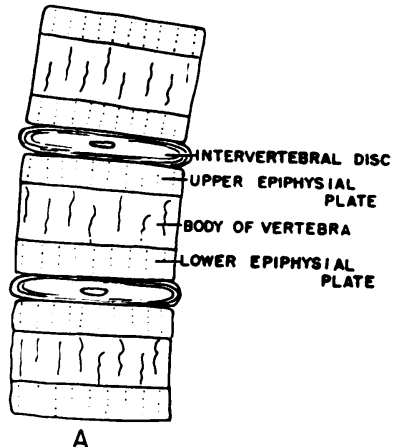

A.

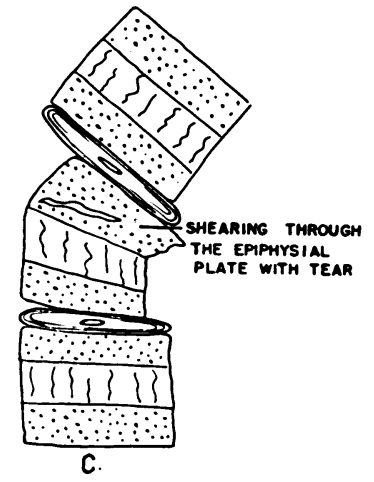

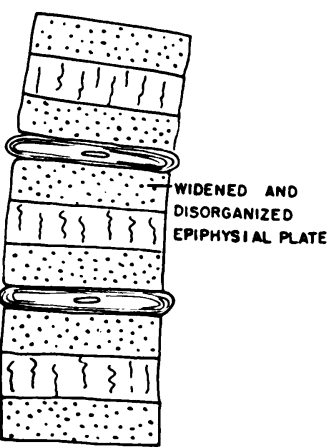

B.

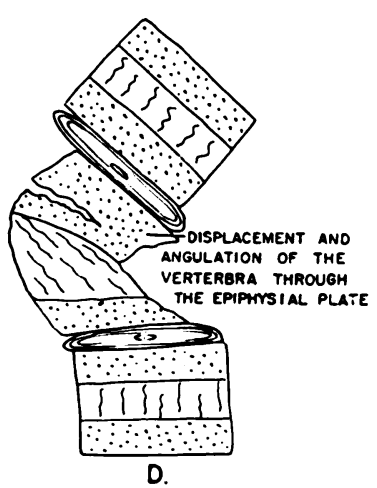

FIG. 7

The mechanism of the spinal deformity that occurs in rats fed on semicarbazide is shown here diagrammatically.

The normal epiphysial plate is narrow and shows an orderly and regular arrangement of the following zones: the zone of resting cartilage, the zone of proliferating cartilage, the zone of maturing cartilage, the zone of calcifying cartilage (Fig. 8). As there is a coordinated sequence of cellular processes, proceeding in equilibrium, the dimensions of the various zones are kept constant (Sissons 1956). There are three dynamic mechanisms in the metabolism of the epiphysial plate in its orderly regimented process of endochondral ossification:

1. The energy mechanism: $(a)$ glycolytic cycle, $(b)$ tricarboxylic cycle (Krebs cycle).

2. Synthesis of chondroitin sulphate and ground substance.

3. The mineralisation process.

Both the anaerobic glycolytic cycle and the oxidative tricarboxylic cycle are known to occur in the metabolism of the epiphysial plate. From the available evidence as reviewed by 
Zambotti (1957), the tricarboxylic cycle is more prominent at the zone of maturing cartilage, where there is an abundant supply of oxygen. On the other hand the glycolytic cycle, taking place in the absence of oxygen, is more prominent in the zone of proliferating cartilage, which is the relatively avascular part of the plate (Fig. 8).

Beta aminopropionitrile, semicarbazide and mercaptoethylamine produce more or less similar gross lesions in laboratory animals. In all three conditions there is a widening and disorganisation of the epiphysial plate. But the histology of the epiphysial cartilage in the

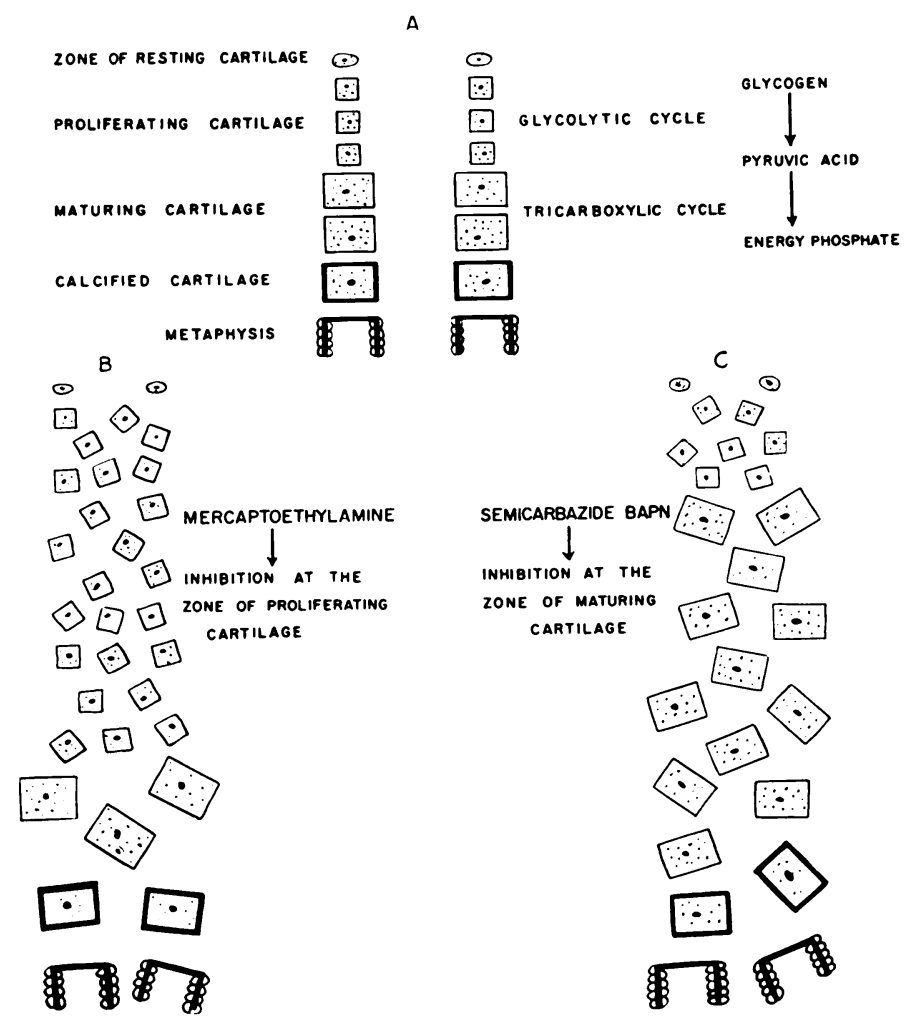

FIG. 8

This diagram shows the epiphysial plate of (A) a normal rat, (B) a rat on mercaptoethylamine, and (C) a rat on either BAPN or semicarbazide. In the normal rat $(A)$ the plate is narrow with an orderly arrangement of the different zones. The zones of the glycolytic cycle and tricarboxylic cycle are also indicated and correspond respectively to the proliferating cartilage and maturing cartilage. In (B) there is disorganisation and maximal widening of the zone of proliferating cartilage. In (C) the disorganisation and maximal enlargement is due to the zone of maturing cartilage.

lesions caused by mercaptoethylamine is significantly different from that produced by BAPN and semicarbazide. In the lesions due to BAPN and semicarbazide, abnormal widening of the zone of maturing cartilage is mainly responsible for the enlargement of the plate (Fig. 10). There is a block to further differentiation at this zone and, as further development is inhibited, there is a disturbance of the equilibrium and an undue widening of this area. In terms of metabolic process, this is the zone of the tricarboxylic cycle and it is possible that these two compounds may affect this cycle (Fig. 8).

On the other hand the lesions due to mercaptoethylamine (Ramamurti and Taylor 1958a) are characterised by a preferential enlargement of the zone of proliferating cartilage from 
interference with further differentiation of this zone (Figs. 8 and 9). The glycolytic cycle is the main metabolic event at this zone. Mercaptoethylamine may affect this cycle. However, these interpretations are mere speculations and must await direct biochemical proof.

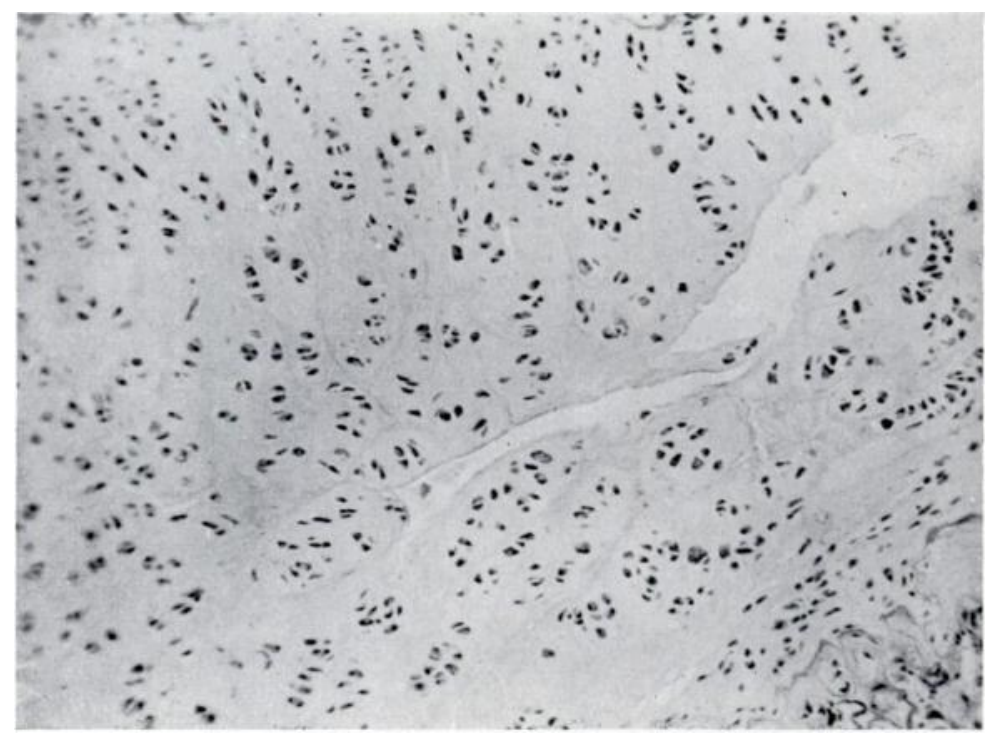

FIG. 9

The upper tibial epiphysial plate of rat fed on mercaptoethylamine for eight weeks shows widening and disorganisation of the epiphysial cartilage mainly due to increased width of the zone of proliferating cartilage which occupies almost the whole width of the plate. (Haematoxylin and eosin, $\times 110$.)

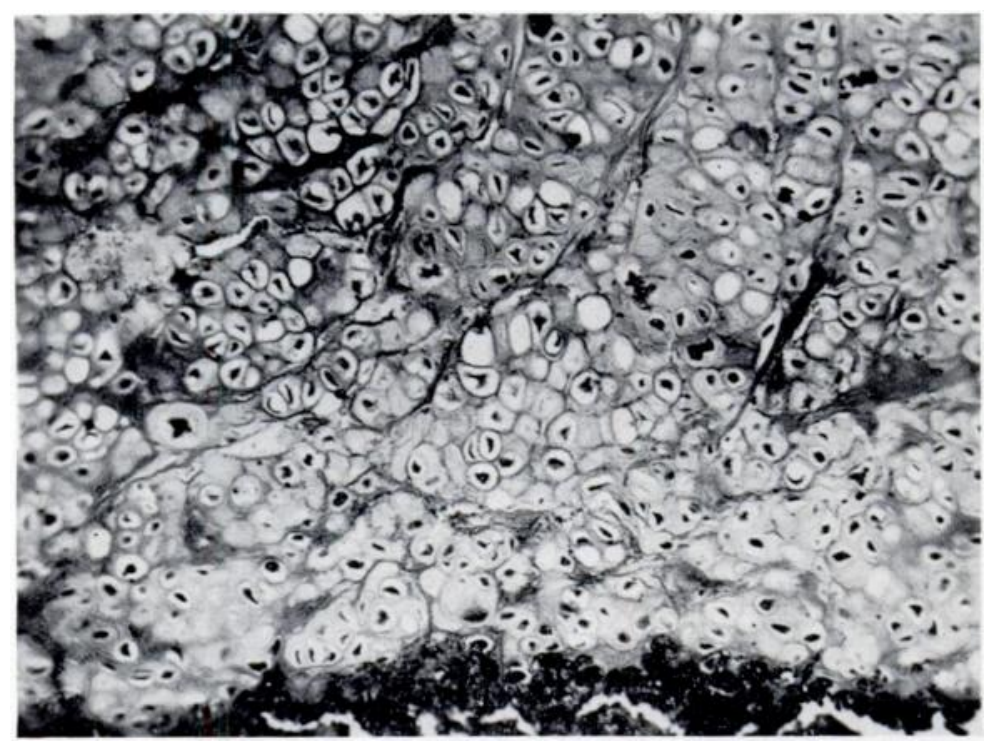

Fig. 10

Compare this epiphysial plate of rat fed on BAPN for four weeks, with that shown in Figure 9.. There is gross disorganisation and marked widening of the zone of maturing cartilage. (Haematoxylin and phloxine, $\times 110$.)

Histochemical study of the lesions produced by all the lathyrogenic compounds shows characteristic alterations in the periodic acid Schiff reaction and at times altered metachromatic staining of the epiphysial plate, which suggests that there is decreased polymerisation of the 
ground substance (Ramamurti and Taylor 1958a). This has been confirmed by other workers (Pyörälä, Punsar, Seppälä and Karlsson 1957).

Ground substance of cartilage consists mainly of glycoproteins, made up of a carbohydrate moiety, chondroitin sulphuric acid and a protein fraction which has not been clearly elucidated. Acetyl galactoseamine sulphate and glucuronic acid occur in a highly polymerised form in chondroitin sulphuric acid. Calkins, Soodak and Bauer (1955) have put forward a tentative scheme based on in vitro enzymatic studies, for the synthesis of chondroitin sulphuric acid which is presented in Table I. Though there is considerable evidence to support it, it has a limitation that in vivo reactions may be different. The prominent chemical participants are: 1) glutamine which combines with the carbohydrate to form glucoseamine-6-phosphate, 2) acetyl co-enzyme A which brings about acetylation, and 3) uridine-tri-phosphate which is active in many carbohydrate reactions.

TABLE I

Tentative scheme for the interconversion of body sugar compounds based on in vitro enzymatic studies. Evidence for the steps designated by the letters $(a),(b),(c)$ and $(d)$ is available. (Modified from Calkins, Soodak and Bauer 1955.)

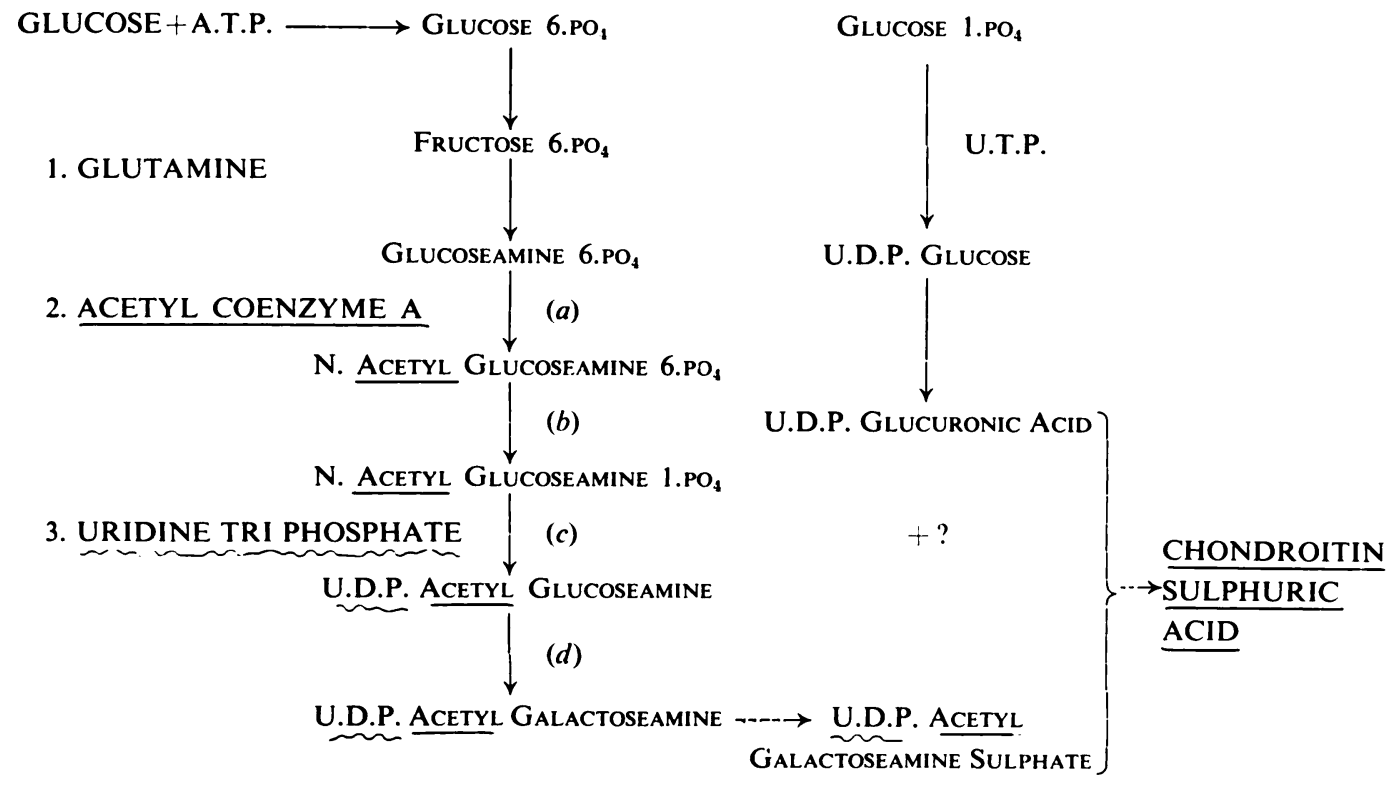

With this scheme as a basis, certain studies were done in this laboratory. Animals receiving BAPN were divided into three groups; one group received 3 per cent glutamine in diet, the second and third groups received parenterally one milligram of co-enzyme $A$ and uridine-tri-phosphate respectively. These were administered daily but did not prevent the development of skeletal lesions, which suggests that the lathyrogenic agents do not exert their influence at these particular sites of the metabolic pathways.

Be that as it may, the indications are that these different compounds produce the characteristic deformities by affecting directly or indirectly the metabolism of the epiphysial cartilage. The lathyrogenic agents are all short-chain organic compounds and have in common an amino group at one end of the chain; the other groups in the compounds vary one from the other. In order to ascertain whether a specific reactive group might be responsible for the biochemical reactions involved in the production of osteolathyrism, a series of chemicals were

VOL. 41 B, No. 3, AUGUST 1959 
selected that bore a close resemblance to the proven lathyrogenic compounds. These chemicals, tabulated in Table II, were fed to experimental animals as a percentage of the diet as indicated. In no instance were skeletal lesions produced. This suggests that the interference with the metabolism of epiphysial cartilage is not mediated through a specific reactive group or chemical configuration.

\section{SUMMARY}

1. Young Wistar rats fed on a diet containing $0 \cdot 3$ per cent semicarbazide hydrochloride developed the characteristic lesions of osteolathyrism. This consisted of kyphoscoliosis, displacement of epiphyses and dislocations of joints. A pathological study of the skeletal lesions showed widening, disorganisation and tears of the epiphysial plate with the zone of

\section{TABLE II}

List of compounds fed to young Wistar rats at the concentrations indicated for ten weeks or more. Compounds marked $\times$ were reported by Wawzonek, Ponseti, Shepard and Wiedenmann (1955) and were not tried in this laboratory. Only the compounds underlined produced skeletal lesions, while the other chemicals resembling these compounds were ineffective.

\section{COMPOUND}

I. $\beta$ AMINO PROPIONITRILE $0.5 \%$

AMINO ACETONITRILE $0.2 \%$

AMINO BUTYRONITRILE $0.2 \%$ '

a AMINO PROPIONITRILE $0.2 \%$

SUC IINONITRILE $0.8 \%$

CYANAMIDE $0.2 \%$

DICYANDIAMIDE $2.0^{\circ}$ 。

II. SEMICARBAZIDE $0.3 \%$

GLYCINEAMIDE $2.0 \%$

GUANYLUREA $2.0 \%$

GUANIDINE $0.6 \%$

AMINOGUANIDINE $0.5 \%$

HYDRAZINE $0.2 \%$

HYDROXYLAMINE $2.0 \%$

PHENYLHYDRAZINE $0.3 \%$

METHYLAMINE $2.0 \%$

ETHYLAMINE $1.0 \%$

III. MERCAPTOETHYLAMINE $0.5 \%$

ETHANOLAMINE $2.0 \%$

\section{FORMULA SKELETAL LESIONS}

\begin{tabular}{|c|c|}
\hline $\mathrm{H}_{2} \mathrm{~N} \mathrm{CH}_{2} \mathrm{CH}_{2} \mathrm{CN}$ & $+t+$ \\
\hline $\mathrm{H}_{2} \mathrm{~N} \mathrm{CH}_{2} \mathrm{CN}$ & +++ \\
\hline $\mathrm{H}_{2} \mathrm{~N} \mathrm{CH}_{2} \mathrm{CH}_{2} \mathrm{CH}_{2} \mathrm{CN}$ & - \\
\hline $\mathrm{CH}_{3} \mathrm{CHNH}_{2} \mathrm{CN}$ & - \\
\hline $\mathrm{CN} \mathrm{CH} \mathrm{CH}_{2} \mathrm{CN}$ & - \\
\hline $\mathrm{H}_{2} \mathrm{~N} \mathrm{CN}$ & - \\
\hline $\mathrm{H}_{2} \mathrm{~N} \mathrm{CN} \mathrm{HNH} \mathrm{CN}$ & - \\
\hline $\mathrm{H}_{2} \mathrm{~N} \mathrm{NH} \mathrm{CO} \mathrm{NH}_{2}$ & $t+t$ \\
\hline $\mathrm{H}_{2} \mathrm{~N} \mathrm{CH}_{2} \mathrm{CO} \mathrm{NH}_{2}$ & - \\
\hline $\mathrm{H}_{2} \mathrm{~N} \mathrm{CN} \mathrm{HNH}$ CO $\mathrm{NH}_{2}$ & - \\
\hline $\mathrm{H}_{2} \mathrm{~N} \mathrm{NHC} \mathrm{NH_{2 }}$ & - \\
\hline $\mathrm{H}_{2} \mathrm{~N}$ CNH NH $\mathrm{NH}_{2}$ & - \\
\hline $\mathrm{H}_{2} \mathrm{~N} \mathrm{NH}_{2}$ & - \\
\hline $\mathrm{H}_{2} \mathrm{~N} \mathrm{OH}$ & - \\
\hline $\mathrm{H}_{2} \mathrm{~N} \mathrm{NH} \mathrm{C}_{6} \mathrm{H}_{3}$ & - \\
\hline $\mathrm{H}_{2} \mathrm{~N} \mathrm{CH}_{3}$ & - \\
\hline $\mathrm{H}_{2} \mathrm{~N} \mathrm{CH}_{2} \mathrm{CH}_{3}$ & - \\
\hline $\mathrm{H}_{2} \mathrm{~N} \mathrm{CH}_{2} \mathrm{CH}_{2} \mathrm{SH}$ & ++ \\
\hline $\mathrm{H}_{2} \mathrm{~N} \mathrm{CH}_{2} \mathrm{CH}_{2} \mathrm{OH}$ & - \\
\hline
\end{tabular}

maturing cartilage showing the greatest increase in width. The severe kyphoscoliosis was due to a derangement and displacement at and through the epiphysial plates of the twelfth thoracic or first lumbar vertebra.

2. Some of the compounds that are known to produce osteolathyrism in laboratory animals are beta aminopropionitrile, amino acetonitrile, mercaptoethylamine and semicarbazide. The mode of action of the lathyrogenic compounds was analysed in the light of a number of experiments done in this laboratory.

3. It is possible that they interfere with the metabolism of the epiphysial plate. There appears to be a decreased polymerisation of the ground substance of the epiphysial cartilage, but the exact metabolic reaction involved is not known. Other chemicals of similar structure, 
with the same reactive groups, did not show lathyrogenic properties. It is concluded that it is not a particular chemical structure, configuration or specific reactive group that is responsible for the production of osteolathyrism. The chemistry of the lesions still remains to be solved.

We are grateful to Dr L. D. Hayward, Assistant Professor, Department of Chemistry, University of British Columbia, for his interest and advice and we also wish to thank Mrs H. Cheney, Mrs M. Hendry, Mrs K. Morris and $\mathrm{Mr} \mathrm{B}$. J. Twaites for their kind assistance.

This work was supported in part by grants from: the Canadian Arthritis and Rheumatism Society, B.C. Division: the Orthopaedic Medical Board Fund of the Vancouver General Hospital; and the Koerner Foundation, University of British Columbia.

\section{REFERENCES}

Calkins, E., Soodak, M., and Bauer, W. (1955): Metabolism and Clinical Significance of the Carbohydrate Components of Connective Tissue. New England Journal of Medicine, 253, 865.

Dasler, W. (1958): Production by Semicarbazide of Gross Skeletal Changes in Rats Similar to Osteolathyrism. Proceedings of the Society for Experimental Biology and Medicine, 97, 112.

Pyörälä, K., Punsar, S., Seppälä, T., and Karlsson, K. (1957): Mucopolysaccharides of the Aorta and Epiphysial Cartilage in Lathyritic Growing Rats and Rat Fetuses. Acta Pathologica et Microbiologica Scandinavica, 41, 497.

Ramamurti, P., and Taylor, H. E. (1958a): Histochemical Studies of the Evolution and Regression of Skeletal Deformities Due to Beta-aminopropionitril (BAPN). Laboratory Investigation, 7, 115.

Ramamurti, P., and Taylor, H. E. (1958b): Skeletal Lesions Produced in Rats by Feeding BetaMercaptoethylamine. Archives of Pathology, 66, 270.

Selye, H. (1957): Lathyrism. Revue Canadienne de Biologie, 16, 1.

Sissons, H. A. (1956): The Growth of Bone. The Biochemistry and Physiology of Bone, p. 443. Edited by C. H. Bourne. London: Academic Books Ltd.

Wawzonek, S., Ponseti, I. V., Shepard, R. S., and Wiedenmann, L. G. (1955): Epiphyseal Plate Lesions, Degenerative Arthritis, and Dissecting Aneurysm of the Aorta Produced by Aminonitriles. Science, $121,63$. Zambotri, V. (1957): The Biochemistry of Preosseous Cartilage and of Ossification. Scientia Medica Italica (English Edition), 5, 614.

vol. 41 B, No. 3. AUGUSt 1959 